\title{
Predictors of Online Cancer Prevention Information Seeking Among Patients and Caregivers Across the Digital Divide: A Cross-Sectional, Correlational Study
}

Tamar Ginossar, BA, MA, PhD

University of New Mexico Cancer Center, Department of Communication and Journalism, University of New Mexico, albuquerque, NM, United States

\section{Corresponding Author:}

Tamar Ginossar, BA, MA, PhD

University of New Mexico Cancer Center

Department of Communication and Journalism

University of New Mexico

Albuquerque, NM,

United States

Phone: 15058849251

Fax: 15052775305

Email: ginossar@unm.edu

\section{Abstract}

Background: The digital divide is a recognized public health problem caused by social determinants that exacerbate health disparities. Despite the "tectonic shift" in how most of the public obtains cancer information, underserved communities are at increased risk of being digitally marginalized. However, research that examines factors underlying eHealth information seeking in diverse health contexts is lacking.

Objective: The aim of this paper is to explore preferences and use of eHealth cancer prevention information (CPI) among patients and caregivers attending a minority-serving oncology clinic using the comprehensive model of information seeking as a theoretical framework. Specifically, the study examined the role of social determinants and prevention orientation in differences in preference and use of the Internet for CPI seeking among this diverse sample.

Methods: Survey methodology was used to identify social determinants and behavioral factors, including prevention orientation as correlates and predictors of respondents' $(n=252)$ preferences and use of eHealth for CPI seeking.

Results: Less than half $(112 / 252,44.4 \%)$ of respondents said that if faced with the need to seek CPI, they would seek this information online. In the final logistic regression model, education, ethnicity, age, and prevention orientation made significant contributions to the model $(P<.05)$. Specifically, for each year increase in age, participants were $3 \%$ less likely to use the Internet for CPI seeking $(P=.011)$. Compared to college graduates, respondents who did not complete high school were 11.75 times less likely to cite the Internet as a CPI carrier $(P<.001)$ and those with a high school education were 3 times $(2.99, P=.015)$ less likely. In addition, the odds that a Spanish speaker would cite the Internet as a CPI carrier were one-fifth (22\%) of non-Hispanic whites $(P=.032)$ and about one-quarter $(26 \%)$ of English-speaking Latinos $(P=.036)$. Finally, with each one point increase on the prevention orientation scale, respondents were 1.83 times less likely to cite online CPI seeking $(P=.05)$.

Conclusions: Social determinants to health have profound influence on eHealth CPI seeking. Providers and policy makers should focus on meeting patients and family members' CPI needs following diagnosis and increase eHealth accessibility and availability of evidence-based CPI to diverse populations. Future research is needed to unravel further differences in eHealth CPI seeking, including those among Native Americans that emerged as an additional digitally underserved racial/ethnic group. Finally, additional factors underlying these differences should be explored to better tailor CPI eHealth information to diverse communities' information needs.

(JMIR Cancer 2016;2(1):e2) doi: 10.2196/cancer.5108

\section{KEYWORDS}

digital divide; Internet, information seeking behavior; minority health 


\section{Introduction}

\section{Overview}

The exclusion of ethnic and racial minorities and vulnerable populations from accessing Web-based health information [1-3] exacerbates cancer-related health disparities. Despite a "tectonic shift" in how cancer patients and their families obtain information and make decisions about their health, including primary and secondary prevention [4], 1 in 5 American adults does not use the Internet. These nonusers are disproportionally likely to be senior citizens, Spanish speakers, adults with less than a high school education, people with low income [5], and cancer survivors [6]. In view of the mounting evidence on the prevalence and demographic predictors of online health information inequities in the general public [3], scholars noted the importance of examining the digital divide in communities that cope with specific health concerns [7].

The goal of this study is to examine use of the Internet for cancer prevention information (CPI) seeking among cancer patients and their families attending a minority-serving academic cancer center in New Mexico, United States, a minority-majority state with the lowest national rate of Internet access at home [8]. The need for this study stems from the importance of eHealth CPI for people diagnosed with cancer and their families. CPI is necessary to inform lifestyle- and screening-related behavior changes. Adhering to evidence-based preventive practices may reduce the likelihood of cancer reoccurrence following remission, reduce second primary cancer diagnosis among cancer survivors, improve overall health outcomes, and reduce anxiety among this population [9,10]. Although people diagnosed with cancer and their families consistently report that they are interested in CPI [11], these needs are rarely met in the medical encounter [12]. A recent study revealed that ethnic and racial minority patients and caregivers value CPI but are often blocked from seeking it [13]. It is likely that the digital divide contributes to the barriers they experience, but past studies did not explore use of the Internet for CPI seeking in this population.

Consistent with the theoretical framework of the comprehensive model of information seeking (CMIS) [14,15], this study aimed at understanding preferences and actual use of the Internet for CPI seeking among diverse patients and their families with the goal of informing a future intervention. Following the CMIS, this study examined factors that are consistent with social determinants to health and have been shown to distinguish between eHealth users and nonusers [16] as well as additional behavioral- and individual-level factors including past CPI-seeking behaviors and prevention orientation [17-19].

\section{Theoretical Background}

The CMIS [14,15] provides a theoretical framework for this research developed to explain and predict cancer-related health information seeking and source utilization and has been tested in diverse settings [14,15,20-23] including online communication environments [24]. Integrating concepts from uses and gratification research, the health belief model, and a model of media exposure and appraisal, the CMIS proposes three primary levels of variables that influence cancer information seeking. Antecedent factors, such as demographics, beliefs, and attitudes constitute the first level, factors related to the information sources comprised the second level, and the third level includes specific information-seeking behaviors $[15,25]$. According to this model, the antecedents determine the underlying imperatives to seek information; the perceived characteristics of the information carriers influence the intentions to seek information from particular carriers; and the information-seeking actions are the outcomes of the antecedents and the characteristics of the information carriers [21].

\section{Cancer Prevention Information Seeking Among Survivors and Caregivers}

Whereas some patients might perceive CPI as irrelevant or stressful [26,27], review of the literature concluded that CPI constitutes an important information need, comprising $30 \%$ of patient information needs [11]. This information need is likely related to the increased risk of secondary diagnoses and reoccurrence following remission among cancer survivors [11]. Additionally, people diagnosed with cancer might also be interested in receiving information in order to support their families in preventing cancer or to better understand the etiology of their illness. Diagnosis of cancer in the family also leads to heightened perceptions of cancer risk and cancer worry among family members [28], which often result in CPI needs [29]. Obtaining CPI is necessary in making informed decisions about cancer prevention and can reduce anxiety [9], but only one-fifth of oncologists provide this information [12].

Cancer patients vary their source utilization in accordance with the type of information they seek [30]. It is therefore essential to examine use of the Internet for CPI seeking, but most studies to date focused on general cancer information seeking among cancer patients [6,22,31-33]. Additionally, studies that examined CPI seeking and source utilization following diagnosis recruited predominantly non-Hispanic white college graduates $[22,30,34,35]$, and their findings might not be generalized to more diverse patient populations. A recent community-based study of CPI seeking among a diverse sample of cancer patients and their families documented that ethnic minorities and those with lower social economic status (SES) were less likely to seek CPI compared to other respondents despite equal or higher perceptions of its importance and motivation to receive it [13]. Experiencing barriers to online access might contribute to this disparity [6], but eHealth preferences and use of CPI seeking following diagnosis among diverse people diagnosed with cancer and their loved ones was not previously examined. According to the CMIS [14,15], information seeking along the cancer continuum involves different mindsets and is motivated by different needs. Therefore, it is important to better understand CPI seeking following diagnosis with cancer rather than assume it follows patterns identified in different populations or cancer information seeking contexts. Such an understanding is essential for designing health communication and education efforts for this population.

According to the CMIS, there are inherent differences in cancer information seeking among the general public and those who cope with a cancer diagnosis. Whereas the first type of information seeking is taking place "when someone is not confronted with the symptoms or disease, but may be mildly 
concerned with prevention [21]," persons who seek information following diagnosis cope with a pressing and acute problem, which is "novel and fraught with emotional complications [21]." In view of this difference in information seeking that distinguishes those who seek CPI following cancer diagnosis from the general public, it is important to explore CPI seeking following cancer diagnosis. Use of the CMIS to examine use of the Internet for CPI seeking can shed more light on this important experience and its predictors.

\section{Antecedents to Internet Use in Cancer Prevention Information Seeking}

Consistent with the CMIS, this study examines whether certain antecedents are related to seeking CPI online among cancer patients and their families who attend an ambulatory care oncology clinic at a National Cancer Institute (NCI)-designated minority-serving cancer center. The following factors were identified in past research that identified social determinants of CPI seeking online among the general population [36-39] and among those following diagnosis [40].

\section{Social Determinants of Online Cancer Prevention Information Seeking}

As previously mentioned, older adults, those with low SES or health status, and cancer survivors are less likely to seek health information online $[25,41,42]$. Ethnic minority cancer patients and their families have lower rates of accessing the Internet to seek cancer-related information compared to non-Hispanic whites [43]. According to national survey data, Latinos are considered the most digitally disadvantaged ethnic group in the United States [44]. In addition to having less access to the Internet, Latinos also hold different perceptions of its utility [45]. These disparities are related to inequalities in the propensity to seek CPI and lack of availability of Spanish language information resources [39]. Because English emerges as the most significant predictor of health information seeking among Latinos [46,47], it is important not to conflate Latino ethnicity with limited English proficiency and to examine experiences of monolingual Latino Spanish speakers as well as those who are fluent in English. Whereas national surveys document the digital divide among Latinos, telecommunication evidence suggests that Native American communities are the most digitally marginalized [48]. Because they are not included in most national surveys such as those conducted by the NCI $[33,49-58]$ and the Pew Research Center $[5,46,59,60]$, the impact of the digital divide on health information seeking among Native Americans remains largely unknown.

\section{Motivation to Seek Cancer Prevention Information}

In contrast to the role of social determinants of cancer health information-seeking behavior and the digital divide including race/ethnicity, education, income, and other demographic factors [33], not much is understood about the role of other psychosocial factors in seeking CPI online. A potential antecedent that can relate to CPI seeking online is motivation, an important variable in health information seeking [61]. Individuals' motivation to be healthy leads to their interest in health issues and active engagement in information seeking, including selection of new information technologies [17]. Specifically, individuals' prevention orientation, or health consciousness, is likely to influence online CPI seeking [62]. A construct of health orientation [17], prevention orientation measures the degree to which individuals feel that preventive behavior is important to them and worthy of engaging in. It is thought to be a personality construct that is influenced by specific health contexts [17]. Prevention orientation is related to different health behaviors including online support group participation [17,62] and CPI seeking among minority cancer patients and caregivers [13]. Research revealed that among the general population, health information seeking online is related to higher levels of health orientation [63]. However, it is unknown to what degree it is related to use of the Internet as a CPI carrier.

Following the CMIS $[14,15]$ and previous studies that examined the manifestation of digital inequities in cancer information seeking as described above [22,25,64], the current research goal was to examine predictors of online CPI seeking among a diverse sample of people diagnosed with cancer and their families. Moreover, research indicated the importance of understanding individuals' preferred sources, conceptualized as information sources they indicate they would use if faced by an information need as well as the information sources they actually use [33]. Therefore, this study aimed at understanding both correlates and predictors of preference for the Internet as a CPI carrier and differences among those who sought CPI online and those who sought it offline. To learn about eHealth CPI seeking among a diverse sample of people diagnosed with cancer and their families, the following research questions were posed:

RQ1: What are the factors associated with citing the Internet as a CPI carrier among cancer patients and their families?

RQ2: What are the factors associated with online and offline CPI seeking among cancer patients and their families?

\section{Methods}

\section{Overview}

This is a cross-sectional, correlational study using secondary data analysis of a study that examined CPI seeking among a diverse sample of people diagnosed with cancer and their families. Individuals were eligible to participate if they were 18 years of age or older and receiving care at a NCI-designated minority-serving cancer center in New Mexico (referred to as patients) or were accompanying a person receiving care (referred to as caregivers). The study was approved by the institutional review boards of the University of New Mexico and its cancer center, and informed consent was obtained from all participants.

\section{Recruitment}

Direct recruitment approach $[65,66]$ and the screening strategy for oversampling minority participants [67] were used to recruit hard-to-reach patient populations $[65,66]$ in the context of ethnic-related health disparities [68-70]. Response rate was 91\%. Patients and caregivers who declined cited reasons including lack of English/Spanish proficiency, emotional state, and lack of interest. Of the 252 individuals recruited, 105 were caregivers. The largest group $(56 / 105,53.3 \%)$ included spouses of patients, followed by adult children $(29 / 105,27.6 \%)$ and 
other family members $(20 / 105,19.0 \%)$. One caregiver identified as a friend.

Participation included answering a survey in English (214/252, $84.9 \%$ ) or in Spanish $(38 / 252,15.1 \%)$, according to participants' preference. A bilingual, bicultural research team member was available to answer questions and requests for clarification. Participants were offered to have the survey read by the interviewer/research team member. A total of 54 participants preferred to have the survey read to them, and a team member read each question out loud, ensured that participants understood the questions, and filled in the participants' answers. Respondents received a $\$ 10$ gift card to a local grocery store as compensation for participation. Participants' demographic information is presented in Table 1.

Table 1. Personal characteristics.

$\mathrm{N}(\%)$

Gender

Women

$94(37.3)$

Men

$157(62.3)$

Patient/relative

\section{Patient}

Relative

$108(42.9)$

Marital status

Married/live with a partner

Not married

Missing

\section{Race/ethnicity}

American Indian/Native American

Latino-Spanish speaking

$36(14.3)$

Latino-English speaking

$131(52.0)$

Other (African American \& Asian)

$10(4.0)$

Non-Hispanic white

$58(23.0)$

\section{Education}

Less than high school

High school graduate

Some college/training

College graduate

Missing

Annual household income

$<\$ 20,000$

115 (45.6)

$\$ 20,001-\$ 35,000$

39 (15.5)

$\$ 50,001-\$ 70,000$

28 (11.1)

$>\$ 70,001$

Missing

Uninsured

Insured

Language of survey

Missing 


\section{Measures}

\section{Antecedents}

Sociodemographic questions pertained to gender, age, education, household income, marital status, and clinical information including self-reported health status. The following measures were used to examine perceptions and experiences that might influence CPI seeking online.

Behavioral-related measures consisted of prevention orientation, previous CPI seeking, past use of the Internet for CPI seeking, and health information-seeking experiences. All the survey measures have been tested in prior research and were reliable and valid, as described in the following sections.

Prevention orientation related to respondents' motivation to engage in healthy behaviors including health information seeking. It was measured by the prevention orientation subscale, which was previously tested and validated [17] and comprises five items. Examples include "Living life in the best possible health is very important to me" and "Eating right, exercising, and taking preventive measures will keep me healthy for life." Responses were measured on a scale ranging from 1 to 5 with 1 representing strongly disagree and 5 representing strongly agree. The Cronbach alpha for this measure was .88 .

Past CPI-seeking behavior was measured using Health Information Trends Survey (HINTS) items [33,52]. Participants were asked whether they have looked for information about cancer prevention: "Have you ever looked for information about cancer prevention?" and "When was the last time you searched for information about how to prevent cancer?" Responses to the second question were coded as prior CPI seeking when respondents indicated a time when they sought CPI and no prior CPI seeking when they did not indicate such search. Cronbach alpha was assessed at .98 .

Health information-seeking experiences were measured by examining respondents' evaluation of the difficulty of CPI seeking. The 6 HINTS items included statements such as "It took a lot of effort to get the information that I needed" and "The information I found was too hard to understand." This scale reliability has been previously tested [71] and determined to have a Cronbach alpha of .84 .

\section{Outcome Measures}

Selection of the Internet as a CPI carrier was the primary outcome measure. Following the HINTS instrument that examined cancer information seeking [72], we asked all respondents where they would go first for information about cancer prevention and asked those who previously sought CPI to indicate the information sources they used [72]. Responses to these open-ended questions were coded as a binary variable that referred to whether respondents listed the Internet as a CPI source or not. The coders were two doctoral research assistants, and they met for one training session that consisted of directions on coding the responses as online when participants' referenced the Internet. Such references included listing specific websites or mentioning the Internet as a general information source for CPI. Coder were instructed to code entries as offline when no reference to online sources was mentioned. Following this session, they coded the responses individually and met again to compare their results. Intercoder reliability was computed at $98 \%$; the Krippendorff alpha was .96 .

\section{Analysis}

Analysis was conducted using SPSS version 22 software (IBM Corp). First, to determine the sample's demographic characteristics, chi-square tests were used to examine categorical variables and $t$ tests were used to examine continuous variables. The main outcome of the analysis of the first research question was whether respondents cited the Internet as a CPI carrier they would turn to if faced with a CPI need. These results are listed in Multimedia Appendix 1.

Missing values ranged from $0 \%$ to $5 \%$ in all variables, so listwise deletion was used for categorical variables and mean substitution was used for continuous variables. The final logistic model indicates those variables remaining statistically significant at the .05 level and is presented in Multimedia Appendix 1 .

The main outcome in answering the second research question included actual use of the Internet by respondents who sought CPI. Analysis of differences between online and offline CPI seekers was conducted using the $t$ test and chi-square test as indicated.

\section{Results}

\section{Selecting the Internet As a Cancer Prevention Information Carrier}

To answer the first research question, which examined factors that distinguished respondents who cited the Internet as an information carrier they would turn to if faced with a CPI need from those who did not, analysis of the answers by all respondents to the survey $(n=252)$ was performed. Less than half $(112 / 252,44.4 \%)$ of respondents said that if faced with the need to seek CPI, they would seek this information online. Differences between respondents who cited the Internet as a CPI carrier and those who did not are described in the subsequent section and detailed in Multimedia Appendix 1.

\section{Demographic Variables}

Women (74/157, 47.0\%) and men (38/93, 41.0\%) did not differ significantly in citing the Internet as a CPI source, as indicated in the chi-square test $\left(\chi_{1, \mathrm{~N}=251}^{2}=0.93, P=.36\right)$. Family members $(56 / 108,52.0 \%)$ were more likely than patients $(44 / 143,39.0 \%)$ to report that they would use the Internet for CPI, with a chi-square test showing that this difference was statistically significant $\left(\chi_{1, \mathrm{~N}=251}^{2}=4.01, P<.05\right)$. Differences in marital status of respondents who cited the Internet as a CPI source $(71 / 147$, $48.1 \%)$ and those who did not $(39 / 100,39.0 \%)$ were not statistically significant as indicated in chi-square analysis $\left(\chi_{1, \mathrm{~N}=247}^{2}=2.08, P=.15\right)$.

Analysis of ethnic differences in citing the Internet as a CPI source revealed that non-Latino whites $(35 / 78,60 \%)$, followed by Latinos who answered the survey in English $(64 / 128,50.0 \%)$ were the most likely to select the Internet as a CPI source, compared to about one-third of Native Americans (6/17) and African Americans and Asians (3/10) and only $10 \%$ of Latinos 
who filled in the survey in Spanish (4/38). Chi-square analysis revealed that ethnic differences in selecting Internet for CPI seeking were statistically significant $\left(\chi_{4, \mathrm{~N}=251}^{2}=26.64, P=.00\right)$.

Level of education attained was related to respondents' indication that they would use online CPI sources. Whereas only one-tenth $(5 / 52)$ of those who did not graduate high school cited the Internet as a CPI carrier they would turn to, almost half $(26 / 59,44 \%)$ of high school graduates, over half $(43 / 83$, $52 \%$ ) of those with some post high school education, and two-thirds $(37 / 56,67 \%)$ of college graduate respondents would use online CPI sources. Chi-square analysis revealed that differences in educational attainment between those selecting Internet for future CPI seeking and those who did not were statistically significant $\left(\chi_{3, \mathrm{~N}=249}^{2}=38.96, P=.00\right)$.

Income was also related to citing the Internet as a CPI source. Less than one-third (34/117) of those who have annual household income of less than $\$ 20,000$ said they would use the Internet for CPI seeking, but $71 \%$ of those in the highest income bracket in this study would seek CPI on the Internet (27/38). Additional differences are presented in Multimedia Appendix 1.

Differences in income levels in citing the Internet as a CPI source were statistically significant $\left(\chi_{4, \mathrm{~N}=251}^{2}=28.26, P=.00\right)$. Respondents with medical insurance were more likely to cite the Internet as a CPI carrier (47.5\%) than the uninsured (29.2\%). Chi-square testing showed that this difference was statistically significant $\left(\chi_{1, \mathrm{~N}=250}^{2}=5.30, P<.05\right)$. Almost half of insured respondents (96/199) cited the Internet as a CPI source compared to $29 \%$ of uninsured respondents (14/48). Chi-square test revealed that this difference was statistically significant $\left(\chi_{1, \mathrm{~N}=250}^{2}=5.30, P<.05\right)$.

Language of survey was significantly associated with citing the Internet as a CPI carrier. Half of participants (108/213) who answered the survey in English cited the Internet as a CPI carrier they would turn to compared to only a tenth of respondents who answered in Spanish (4/38). The chi-square test showed that the difference was significant $\left(\chi_{1, \mathrm{~N}=247}^{2}=5.70, P<.05\right)$.

Participants who cited the Internet as a CPI source were significantly younger (mean 51.2 years [SD 12.56]) than those who would not use the Internet for CPI seeking (mean 55.8 [SD 12.99], $\left.t_{249}=-2.82, P<.01\right)$. Time since diagnosis of those who cited the Internet as a CPI sources (mean 32.09 months [SD 4.24]) and of those who did not cite the Internet (mean 29.40 [SD 38.45]) was not statistically significant $\left(t_{241}=0.52, P=.60\right)$.

Individuals who cited the Internet as a CPI source had better self-reported health (mean 2.73 [SD 1.00]), compared to those who did not think they would use the Internet as a CPI source (mean 3.18 [SD 1.01]). A $t$ test revealed that these differences were statistically significant $\left(t_{248}=-3.52, P<.01\right)$. Individuals who cited the Internet as a CPI carrier had lower levels of prevention orientation (mean 4.17 [SD 0.54]) compared to those who would not search CPI online (mean 4.34). These differences were statistically significant $\left(t_{247}=-3.41, P<.01\right)$.
Almost half of participants who sought CPI in the past believed that they would use the Internet for CPI seeking if faced with CPI need compared to $41 \%$ of those who did not previously sought CPI $(n=46 / 113)$, a difference that did not reach statistical significance as indicated in chi square analysis $\left(\chi_{1, \mathrm{~N}=249}^{2}=1.48\right.$, $P=.25)$.

Participants who used the Internet in the past for CPI seeking were more likely to cite the Internet as a CPI carrier compared to those who did not previously use the Internet for CPI seeking. Only 28\% (18/58) of those who did not use the Internet in the past to seek CPI believed that they would use it in the future, whereas a majority $(46 / 64,72 \%)$ of those who sought CPI online in the past responded that they would use it in the future. Chi-square analysis revealed that these differences were statistically significant $\left(\chi_{(1, \mathrm{~N}=246)}^{2}=16.55, P=.00\right)$.

\section{Predictors of Selecting the Internet for Cancer Prevention Information Seeking}

Logistic regression analysis was conducted to answer the first research question and determine which independent variables predicted citing the Internet as a CPI carrier. Included were variables significantly related to differences in citing the Internet as a CPI carrier in the previous analysis (status as patient or caregiver, race/ethnicity, education, age, health status, and prevention orientation). Income and medical insurance were not included due to multicollinearity. A test of the full model against a constant only model was statistically significant, indicating that the predictors as a set reliably distinguished between participants who cited the Internet as a CPI carrier they would turn to and those who did not $\left(\chi_{8, \mathrm{~N}=247}^{2}=71.7, P=.00\right.$, Nagelkerke $\mathrm{R}^{2}=.319$ ).

Education, ethnicity, age, and prevention orientation made significant contributions to the model $(P<.05)$. Specifically, the odds of citing the Internet as a CPI carrier are lower with age. For each year increase in age, participants are 3\% less likely to use the Internet for CPI seeking $(P=.011)$. Education also contributed significantly to the model. Compared to college graduates, respondents who did not complete high school were 11.75 times less likely to cite the Internet as a CPI carrier $(P=.00)$, and those with a high school education were three times $(2.99, P=.015)$ less likely to cite the Internet as a CPI carrier compared to college graduates. The odds that a Spanish speaker would cite the Internet as a CPI carrier were one-fifth $(22 \%)$ of that of non-Hispanic whites $(P=.032)$ and about one-quarter (26\%) of English-speaking Latinos $(P=.036)$. Other ethnic/racial differences were not significant. Additionally, with each one point increase on the prevention orientation scale, respondents were 1.83 times less likely to cite online CPI seeking $(P=.05)$. Other variables did not contribute to prediction of CPI in a statistically significant way. The results are presented in Multimedia Appendix 2.

\section{Actual Use of the Internet for Cancer Prevention Information Seeking}

Of the 252 respondents to the survey, more than half (133, $52.8 \%$ ) indicated they have previously sought CPI. These individuals were asked where they sought CPI, and their 
responses were analyzed to understand the characteristics of online CPI seekers, defined as those who used the Internet to seek CPI, versus offline CPI seekers, those who used only non-Internet CPI sources. These differences are reported in Multimedia Appendix 1. As indicated in the appendix, most CPI seekers $(75 / 133,56.3 \%)$ used the Internet to search for CPI.

The majority of women who sought CPI used the Internet $(55 / 85,65 \%)$ in contrast to a minority of men $(20 / 48,42 \%)$. These differences were statistically significant as indicated in chi-square analysis $\left(\chi_{1, \mathrm{~N}=133}^{2}=6.62, P<.05\right)$. However, family members who sought CPI were not significantly more likely to use the Internet $(37 / 61,61 \%)$ compared to patients $(38 / 72,53 \%)$ $\left(\chi_{1, \mathrm{~N}=133}^{2}=0.83, P=.38\right)$. Similarly, marital status was not related to CPI seeking online in a statistically significant way $\left(\chi_{1, \mathrm{~N}=133}^{2}=1.08, P=.37\right)$.

Examination of the relationship between ethnic identity and online CPI seeking indicated that non-Latino white CPI seekers were most likely to use the Internet $(26 / 39,67 \%)$, followed by Latinos who completed the survey in English (39/56, 59\%). In comparison, a minority of Latinos who responded in Spanish (5/13, 39\%), Native Americans (3/9, 33\%) and African Americans/Asians $(2 / 6,33 \%)$ who sought CPI did so online. Chi-square analysis revealed that ethnic differences among online and offline CPI seekers did not reach statistical significance $\left(\chi_{4, \mathrm{~N}=133}^{2}=6.81, P=.146\right)$.

Online information seeking was positively associated with educational attainment. Among online CPI seekers, only one had less than high school education (7\%). A minority of high school graduates sought CPI online (9/23, 39\%). In contrast, a majority of participants with some post high school training or education $(37 / 57,65 \%)$ and of those who were college graduates $(38 / 56,71 \%)$ were online seekers. Chi-square analysis indicated that these differences were statistically significant $\left(\chi_{3, \mathrm{~N}=132}^{2}=21.56, P=.00\right)$.

Online information seeking was positively associated with annual household income. A minority $(21 / 54,39 \%)$ of CPI seekers with an annual household income less than $\$ 20,000$ used the Internet for CPI seeking compared to a vast majority $(23 / 27,85 \%)$ of CPI seekers with an annual household income above $\$ 70,000$. Chi-square analysis revealed that these differences were statistically significant $\left(\chi_{4, \mathrm{~N}=132}^{2}=16.05\right.$, $P<.01)$. This information and information about additional income brackets is presented in Multimedia Appendix 1. In addition, medically insured and uninsured CPI seekers were equally likely to seek CPI online, with $56.5 \%$ of CPI seekers using the Internet regardless of their medical insurance status $\left(\chi_{1, \mathrm{~N}=133}^{2}=.00, P=1.00\right)$.

Although the majority of CPI seekers who answered the survey in English were online CPI seekers (70/120, 58.3\%) compared to a minority of respondents who filled in the survey in Spanish $(5 / 13,39 \%)$, the results did not reach statistical significance $\left(\chi_{1, \mathrm{~N}=133}^{2}=1.88, P=.24\right)$. Online information seekers were younger (mean 52.7 [SD 12.30]) than offline CPI seekers (mean 56 [SD 11.90]), but a $t$ test indicated that these results did not reach statistical significance $\left(t_{133}=-1.55, P=.123\right)$. Time since diagnosis was longer (mean 32.9 [SD 38.22]) among online CPI seekers compared to offline CPI seekers (mean 26.72 [SD 35.22]). These results were not statistically significant $\left(t_{133}=0.948, P=.345\right)$. An additional factor that differed between online CPI seekers and offline CPI seekers was health status, with online information seekers reporting better health (mean 2.6 [SD 0.94]) compared to offline CPI seekers (mean 3.2 [SD $0.93])$. This difference was statistically significant $\left(t_{133}=3.52\right.$, $P<.01)$.

The analysis revealed that offline CPI seekers had higher levels of prevention orientation (mean 4.42 [SD 0.44]) compared to online CPI seekers (mean 4.27 [SD 0.50]), and this difference was statistically significant $\left(t_{130}=-1.80, P<.05\right)$. Finally, offline and online CPI seekers reported the same levels of difficulty in accessing information (mean 2.8 [SD 0.94 and 0.82, respectively], $\left.t_{130}=-0.04, P=.97\right)$. The results are presented in Multimedia Appendix 1.

\section{Discussion}

\section{Principal Findings}

The current study applied the CMIS to expand the knowledge on the digital divide in specific clinical settings [25] by examining eHealth use for CPI seeking among an ethnically and socioeconomically diverse sample of people diagnosed with cancer and their caregivers who attend a minority-serving academic cancer center in New Mexico. Borrowing from the CMIS framework, this study examined factors related to social determinants of health and motivation as potential antecedents to CPI seeking. According to the CMIS, certain antecedents determine the type of information sources and channels used as well as overall information behavior. The findings revealed the importance of social determinants as antecedents to CPI eHealth seeking in this population. Consistent with patterns identified in past research on health information behavior and the digital divide [22,25], certain demographic factors, including race/ethnicity, educational attainment, household income, age, gender, and health status are related to the propensity to seek cancer information online. In the regression model, younger age, higher levels of education, being non-Hispanic white or English-speaking Hispanic compared to Spanish-speaking Latino, and reporting better health status were significant predictors of CPI eHealth seeking. These factors have been shown to predict disparities following cancer diagnosis in other cancer-related topics $[1,6]$. Therefore, these findings demonstrate how disparities in use of the Internet are merely one factor within an overall inequity in health information seeking and contribute to the literature that documents how the "double divide" is blocking those who need this information the most from accessing it.

Further, this study contributes to past research that suggested that the CMIS is a useful framework for understanding cancer patients' information source selection and usage on the cancer continuum [24]. This model was originally applied to selection of mass media sources [14], but a growing body of research applies this framework to understand use of online cancer 
information sources [24,31]. The current study reveals the importance and utility of integrating factors related to social determinants to the CMIS in exploring cancer information behavior of diverse populations. An additional strength of the CMIS is its structural flexibility. Applying the CMIS in diverse contexts allows for examination of specific predictors of information behavior. The model highlights the importance of incorporating a variety of factors to account for information seeking across different contexts and the fact that the specific patterns of relationships among variables in the model are contingent on the context [21]. Therefore, the current findings point at the importance of examining CPI seeking of underserved cancer patients and their families rather than assume that their information seeking parallels those of the general public. For instance, in contrast to studies utilizing CMIS that reported no significant correlation between antecedents and characteristics of cancer information sources among the general public [14], this study documented the importance of social determinants in predicting online CPI.

Applying the CMIS framework also led to a deeper understanding of the differences between actual CPI versus hypothetical selection of sources. Clearly, not all individuals are able to seek information or to enact on their preferred information sources. Past research documented some discrepancies between cancer information sources that individuals indicate they would select for actual use [73]. This study examined information preferences along with self-reports of actual use. Participants' perceptions of whether they would use the Internet for CPI seeking were largely consistent with reports of use among CPI seekers, with some exceptions. Ethnicity, income, education, and health status were related both to the rates of citing the Internet as a potential CPI source and reports of its use among CPI seekers. However, some differences were noted. First, although men and women did not differ in a statistically significant way in citing the Internet as a CPI source they would use, women who sought CPI were significantly more likely to use the Internet than men who sought CPI. In addition, although having medical insurance was related to citing eHealth as a CPI source, online and offline CPI seekers were equally likely to have medical insurance. Similarly, family members were more likely to cite the Internet as a CPI source, but family members did not differ significantly from patients choosing to be online versus offline CPI seekers. These findings point at the importance of examining information source preferences as well as actual use.

Exploring different psychosocial factors as predictors of information seeking is an important part of studies utilizing the CMIS $[14,15]$ as well as other research of cancer information behavior. An intriguing finding in the current study relates to the negative correlation between prevention orientation and online CPI seeking. In other words, participants who indicated use of the Internet for CPI seeking scored lower on prevention orientation than those who did not report Internet use. This finding conflicts with past studies that indicated the importance of psychosocial factors on health information behavior following cancer diagnosis [34]. Prevention orientation was positively associated in past studies with seeking CPI even after controlling for other factors [13]. This finding further underscores the importance of considering both context and specific predictors because certain psychosocial factors might be associated differently with certain cancer information behaviors based on the context and content of the information and the information sources utilized. Future studies and in particular studies using a long attitudinal design should examine whether online CPI seeking increases skepticism regarding the importance of prevention and how it might influence cancer prevention behavior such as diet, exercise, and screening practices.

These findings also contribute new insights into the dynamics of the digital divide. Age was a key factor that discriminated between those citing the Internet as a CPI source and those who did not in both bi-variate and multivariate analyses. However, this difference is smaller than previously reported. Specifically, persons who cited the Internet as CPI carrier were on average only 4 years younger than those who did not compared to 10 years' difference reported in past studies [25]. Moreover, difference in age among online and offline CPI seekers was smaller and did not reach statistical significance. This finding is consistent with the prediction that age differences in Internet use would decline over time as older adults increasingly use the Internet [25]. The findings indicate a trend toward persistence of the digital divide in CPI seeking because respondents who previously sought CPI online were more likely to indicate that they would seek CPI online in the future. Future studies should explore the role of intervention in decreasing the digital divide and the impact of such intervention on CPI behavior and prevention-related behaviors such as participation in screening and lifestyle changes.

The results also revealed better self-reported health status among those who cited eHealth as a CPI source versus those who did not. Previous research reported conflicting findings regarding the relationship between health status and online health information seeking [74,75]. It is possible that lower health status is related to seeking treatment information online whereas those who feel healthier focus more resources on CPI seeking. Alternatively, it is possible that those with better health have better access to the Internet or that respondents who seek CPI online are better able to maintain their health. This relationship should be explored in future studies using larger cohorts and following them over time.

\section{Practical Implications}

These disparities in CPI seeking online are particularly concerning because comprehensive cancer centers charged with targeting communities with prevention initiatives do not have overarching strategies to disseminate CPI to cancer survivors and their families [76]. Researchers reported that when barriers to access are removed, the benefits of online information seeking are extended to individuals from underserved communities [24]. Therefore, programs should be designed that consider CPI sources available to the target audiences. While many patients and family members turn to the Internet to seek this information, those who are disfranchised and need this information the most are least likely to receive it.

Since interventions are likely to be conducted in specific geographic communities [77], it is essential that research incorporates understanding of CPI seeking among clinical 
populations in certain locales that necessitate effective recruitment strategies. In contrast to past research that used nationally or state representative phone-based $[25,33,49,51,52,54,55,57,58]$ or mailed surveys [30,34,58], this study employed direct recruitment methods in a specific geographic community $[65,66]$, an approach that has been shown to include individuals from underserved communities [70,78]. This approach facilitated a high response rate among this hard-to-reach population of patients and caregivers. Future interventions should apply similar recruitment methods and measure their effectiveness in engaging individuals.

\section{Limitations and Future Research}

Due to this study's focus on a specific geographical region, its sample consisted entirely of patients and caregivers who attend a minority-serving cancer center in New Mexico. Whereas this focus enriches understanding of specific communities and allows for design of community-based interventions, this sample may not be representative of cancer patients from other regions along certain dimensions, such as the health and digital disparities they experience. Despite sample size that exceeded the initial power analysis to detect differences in this sample, the large proportion of ethnic minority respondents who did not seek CPI likely rendered certain differences between online and offline CPI seekers statistically insignificant. This limitation is concerning as Native Americans are underserved and underresearched in both digital access and health information research. The current findings point to the disparities experienced by Native American respondents, and more research is needed to provide insight on actual use of eHealth for CPI seeking among Native American cancer patients and their families.

Further, this study relied exclusively on self-reported data, which have documented shortcomings including recall bias and social desirability influences. Triangulation of data revealed consistency in participants' accounts of their experiences in information seeking, but ultimately the study reports on respondents' perceptions only. Future research should examine the association between CPI-seeking behavior and additional factors that were not explored in this or in previous studies. For instance, this study did not focus on comparisons between CPI seeking among individuals who cope with different types of cancer, which is associated with differences in seeking general cancer information among patients [34] and might also be related to differences in CPI seeking. In addition, Internet access was not measured in a secondary data analysis; therefore, the reasons behind the reported disparities in eHealth CPI seeking are unknown. Future studies should examine Internet access as well as additional factors that might influence eHealth use including digital and health literacies. This study followed past research that examined disparities in information seeking in binary terms $[22,25]$, a methodological choice that introduced an additional limitation. The digital divide consists of a spectrum of inequalities in use of the Internet [5], and research should examine the nuances of CPI seeking and use of eHealth as well as the relationship between CPI seeking, the specific types of CPI sought, sources used, and outcomes such as knowledge and prevention practices.

\section{Acknowledgments}

This study was funded by American Cancer Society Institutional Review Grant 92-024. The author was supported by National Institutes of Health, National Cancer Institute Grant number 3U10CA086780-10S1.

The author would like to thank the following individuals for their contributions to this project. Data collection and entry were done by Elizabeth Luna, Aubrey Meissnest, Anh Phuong Nguyen, Meghan O’Leary, and Danielle Parker. Carla Sakiestewa provided invaluable administrative help and support. Dr. Melanie Royce generously shared her clinical perspective during the different stages of this project. Dr. John Oetzel advised on the statistical design and analysis of the data. Dr. Michelle Ozbun provided important oversight and support. Finally, I would like to thank the patients and family members who shared their experiences with us.

\section{Conflicts of Interest}

None declared.

\section{Multimedia Appendix 1}

Online and offline CPI seeking among cancer patients and relatives.

[PDF File (Adobe PDF File), 38KB-Multimedia Appendix 1]

\section{Multimedia Appendix 2}

Logistic regression analysis predicting digital divide in citing the Internet as CPI carrier among cancer patients and relatives.

[PDF File (Adobe PDF File), 85KB-Multimedia Appendix 2]

\section{References}

1. Neter E, Brainin E. eHealth literacy: extending the digital divide to the realm of health information. J Med Internet Res 2012;14(1):e19 [FREE Full text] [doi: 10.2196/jmir.1619] [Medline: 22357448] 
2. van Deursen AJ, van Dijk JA. The digital divide shifts to differences in usage. New Media Soc 2014;16(3):507-526.

3. Kontos E. Predictors of eHealth usage: insights on the digital divide from the Health Information National Trends Survey 2012. J Med Internet Res 2014;16(7).

4. Finney Rutten LJ, Agunwamba AA, Wilson P, Chawla N, Vieux S, Blanch-Hartigan D, et al. Cancer-related information seeking among cancer survivors: trends over a decade (2003-2013). J Cancer Educ 2015 Feb 26. [doi:

10.1007/s13187-015-0802-7] [Medline: 25712202]

5. Zickuhr K, Smith A. Digital differences. Washington DC: Pew Internet \& American Life Project; 2012 Apr 13. URL: http:/ /www.pewinternet.org/2012/04/13/digital-differences/ [accessed 2016-02-26] [WebCite Cache ID 6fZxN2E9g]

6. Chou WS, Liu B, Post S, Hesse B. Health-related Internet use among cancer survivors: data from the Health Information National Trends Survey, 2003-2008. J Cancer Surviv 2011 Sep;5(3):263-270. [doi: 10.1007/s11764-011-0179-5] [Medline: 21505861]

7. Anker AE, Reinhart AM, Feeley TH. Health information seeking: a review of measures and methods. Patient Educ Couns 2011 Mar;82(3):346-354. [doi: 10.1016/j.pec.2010.12.008] [Medline: 21239134]

8. Broadband Subscription and Internet Use in New Mexico. Albuquerque NM: Bureau of Business and Economic Research, University of New Mexico; 2013. URL: http://hdl.handle.net/1928/23235 [accessed 2016-02-28] [WebCite Cache ID 6feNT0G3O]

9. Mills ME, Sullivan K. The importance of information giving for patients newly diagnosed with cancer: a review of the literature. J Clin Nurs 1999 Nov;8(6):631-642. [Medline: 10827609]

10. Hong Y. Efficacy of a mobile-enabled Web app (iCanFit) in promoting physical activity among older cancer survivors: a pilot study. JMIR Cancer 2015;1(1):e7.

11. Finney Rutten LJ, Arora NK, Bakos AD, Aziz N, Rowland J. Information needs and sources of information among cancer patients: a systematic review of research (1980-2003). Patient Educ Couns 2005 Jun;57(3):250-261. [doi:

10.1016/j.pec.2004.06.006] [Medline: 15893206]

12. Demark-Wahnefried W, Aziz NM, Rowland JH, Pinto BM. Riding the crest of the teachable moment: promoting long-term health after the diagnosis of cancer. J Clin Oncol 2005 Aug 20;23(24):5814-5830 [FREE Full text] [doi: 10.1200/JCO.2005.01.230] [Medline: 16043830 ]

13. Ginossar T. Disparities and antecedents to cancer prevention information seeking among cancer patients and caregivers attending a minority-serving cancer center. J Commun Healthc 2014;7:93-105. [doi: 10.1179/1753807614Y.0000000053]

14. Johnson J, Meischke H. A comprehensive model of cancer-related information seeking applied to magazines. Human Comm Res 1993 Mar;19(3):343-367. [doi: 10.1111/j.1468-2958.1993.tb00305.x]

15. Johnson JD. Cancer-Related Information Seeking (Health Communication). Cresskill, NJ: Hampton Press; 1997.

16. Wang MP. Digital inequalities of family life information seeking and family well-being among Chinese adults in Hong Kong: A population survey. J Med Internet Res 2014;16(10). [doi: 10.2196/jmir.3386]

17. Dutta MJ, Feng H. Health orientation and disease state as predictors of online health support group use. Health Commun 2007;22(2):181-189. [doi: 10.1080/10410230701310323] [Medline: 17668997]

18. Dutta-Bergman M. Trusted online sources of health information: differences in demographics, health beliefs, and health-information orientation. J Med Internet Res 2003;5(3):e21 [FREE Full text] [doi: 10.2196/jmir.5.3.e21] [Medline: $\underline{14517112]}$

19. Dutta-Bergman MJ. Primary sources of health information: comparisons in the domain of health attitudes, health cognitions, and health behaviors. Health Commun 2004;16(3):273-288. [doi: 10.1207/S15327027HC1603_1] [Medline: 15265751]

20. Johnson JD, Andrews JE, Allard S. A model for understanding and affecting cancer genetics information seeking. Lib Information Sci Res 2002;23(4):335-349.

21. Johnson JD. On contexts of information seeking. In: Information Processing \& Management. Tarrytown, NY, USA: Pergamon Press, Inc; 2003:735-760.

22. Mayer DK, Terrin NC, Kreps GL, Menon U, McCance K, Parsons SK, et al. Cancer survivors information seeking behaviors: a comparison of survivors who do and do not seek information about cancer. Patient Educ Couns 2007 Mar;65(3):342-350. [doi: 10.1016/j.pec.2006.08.015] [Medline: 17029864]

23. Hartoonian N, Ormseth SR, Hanson ER, Bantum EO, Owen JE. Information-seeking in cancer survivors: application of the Comprehensive Model of Information Seeking to HINTS 2007 data. J Health Commun 2014;19(11):1308-1325. [doi: 10.1080/10810730.2013.872730] [Medline: 24742287]

24. Han JY, Wise M, Kim E, Pingree R, Hawkins RP, Pingree S, et al. Factors associated with use of interactive cancer communication system: an application of the comprehensive model of information seeking. J Comput Mediat Commun 2010 Apr;15(3):367-388 [FREE Full text] [doi: 10.1111/j.1083-6101.2010.01508.x] [Medline: 21760702]

25. Cotten SR, Gupta SS. Characteristics of online and offline health information seekers and factors that discriminate between them. Soc Sci Med 2004 Nov;59(9):1795-1806. [doi: 10.1016/j.socscimed.2004.02.020] [Medline: 15312915]

26. Schnoll RA, Wileyto EP, Leone FT, Langer C, Lackman R, Evans T. Is a cancer diagnosis a teachable moment for the patient's relative who smokes? Cancer Causes Control 2013 Jul;24(7):1339-1346 [FREE Full text] [doi: 10.1007/s10552-013-0212-2] [Medline: 23605220] 
27. McBride CM, Emmons KM, Lipkus IM. Understanding the potential of teachable moments: the case of smoking cessation. Health Educ Res 2003 Apr;18(2):156-170 [FREE Full text] [Medline: 12729175]

28. Salim A, Ley EJ, Berry C, Schulman D, Navarro S, Zheng L, et al. Effect of community educational interventions on rate of organ donation among Hispanic Americans. JAMA Surg 2014 Sep;149(9):899-902. [doi: 10.1001/jamasurg.2014.1014] [Medline: 25103273]

29. Salim A, Berry C, Ley EJ, Liou DZ, Schulman D, Navarro S, et al. Increasing intent to donate in Hispanic American high school students: results of a prospective observational study. Transplant Proc 2013;45(1):13-19 [FREE Full text] [doi: 10.1016/j.transproceed.2012.08.009] [Medline: 23375270]

30. Lee C, Ramírez AS, Lewis N, Gray SW, Hornik RC. Looking beyond the Internet: examining socioeconomic inequalities in cancer information seeking among cancer patients. Health Commun 2012;27(8):806-817 [FREE Full text] [doi: 10.1080/10410236.2011.647621] [Medline: 22356137]

31. Shaw BR, Dubenske LL, Han JY, Cofta-Woerpel L, Bush N, Gustafson DH, et al. Antecedent characteristics of online cancer information seeking among rural breast cancer patients: an application of the Cognitive-Social Health Information Processing (C-SHIP) model. J Health Commun 2008 Jun;13(4):389-408 [FREE Full text] [doi: 10.1080/10810730802063546] [Medline: $\underline{18569368]}$

32. Beckjord EB, Arora NK, McLaughlin W, Oakley-Girvan I, Hamilton AS, Hesse BW. Health-related information needs in a large and diverse sample of adult cancer survivors: implications for cancer care. J Cancer Surviv 2008 Sep;2(3):179-189. [doi: $10.1007 / \mathrm{s} 11764-008-0055-0]$ [Medline: $\underline{18792791]}$

33. Hesse BW, Arora NK, Burke BE, Finney Rutten LJ. Information support for cancer survivors. Cancer 2008 Jun 1;112(11 Suppl):2529-2540 [FREE Full text] [doi: 10.1002/cncr.23445] [Medline: 18428201]

34. Smith-McLallen A, Fishbein M, Hornik RC. Psychosocial determinants of cancer-related information seeking among cancer patients. J Health Commun 2011 Feb;16(2):212-225 [FREE Full text] [doi: 10.1080/10810730.2010.522227] [Medline: $\underline{21207310}$ ]

35. Rising C, Bol N, Kreps G. Age-related use and perceptions of eHealth in men with prostate cancer: a Web-based survey. JMIR Cancer 2015 Jun 25;1(1):e6. [doi: 10.2196/cancer.4178]

36. Viswanath K, Ackerson LK. Race, ethnicity, language, social class, and health communication inequalities: a nationally-representative cross-sectional study. PLoS One 2011;6(1):e14550 [FREE Full text] [doi: 10.1371/journal.pone.0014550]

37. Kratzke C, Amatya A, Vilchis H. Breast cancer prevention knowledge, beliefs, and information sources between non-Hispanic and Hispanic college women for risk reduction focus. J Community Health 2015 Feb;40(1):124-130. [doi: 10.1007/s10900-014-9908-9] [Medline: 24989348]

38. Kratzke C, Wilson S, Vilchis H. Reaching rural women: breast cancer prevention information seeking behaviors and interest in Internet, cell phone, and text use. J Community Health 2013 Feb;38(1):54-61. [doi: 10.1007/s10900-012-9579-3] [Medline: 22706805]

39. Waters EA, Sullivan HW, Finney Rutten LJ. Cancer prevention information-seeking among Hispanic and non-Hispanic users of the National Cancer Institute's Cancer Information Service: trends in telephone and LiveHelp use. J Health Commun 2009;14(5):476-486 [FREE Full text] [doi: 10.1080/10810730903032952] [Medline: 19657927]

40. Nagler RH, Gray SW, Romantan A, Kelly BJ, DeMichele A, Armstrong K, et al. Differences in information seeking among breast, prostate, and colorectal cancer patients: results from a population-based survey. Patient Educ Couns 2010 Dec;81 Suppl:S54-S62 [FREE Full text] [doi: 10.1016/j.pec.2010.09.010] [Medline: 20934297]

41. Brodie M, Flournoy RE, Altman DE, Blendon RJ, Benson JM, Rosenbaum MD. Health information, the Internet, and the digital divide. Health Aff (Millwood) 2000;19(6):255-265 [FREE Full text] [Medline: 11192412 ]

42. Chang BL, Bakken S, Brown SS, Houston TK, Kreps GL, Kukafka R, et al. Bridging the digital divide: reaching vulnerable populations. J Am Med Inform Assoc 2004;11(6):448-457 [FREE Full text] [doi: 10.1197/jamia.M1535] [Medline: 15299002]

43. James N, Daniels H, Rahman R, McConkey C, Derry J, Young A. A study of information seeking by cancer patients and their carers. Clin Oncol (R Coll Radiol) 2007 Jun;19(5):356-362. [doi: 10.1016/j.clon.2007.02.005] [Medline: 17399963]

44. Fox S, Livingston G. Latinos Online. Washington, DC: PEW Research Center; 2007. URL: http://www.pewhispanic.org/ [accessed 2016-02-28] [WebCite Cache ID 6fd0HZZNr]

45. Peña-Purcell N. Hispanics' use of Internet health information: an exploratory study. J Medical Lib Assoc 2008;96(2):101. [doi: $10.3163 / 1536-5050.96 .2 .101]$

46. Fox S, Jones S. The social life of health information. Washington DC: Pew Internet \& American Life Project; 2009. URL: http://www.pewinternet.org/2011/05/12/the-social-life-of-health-information-2011/ [accessed 2016-02-28] [WebCite Cache ID 6fd0X8v2i]

47. Jesus M, Xiao C. Predicting Internet use as a source of health information: A "language divide" among the Hispanic population in the United States. Policy \& Internet 2012;4(2):1-11. [doi: 10.1515/1944-2866.1178]

48. Sandvig C. The Hardest Cases of Broadband Policy: Native Telecommunications, Captive States, and Policy Entrainment. 2013 Apr 03 Presented at: TPRC 41: The 41st Research Conference on Communication, Information and Internet Policy; 04/03/2013; Schertz, TX. 
49. Hawkins NA, Berkowitz Z, Peipins LA. What does the public know about preventing cancer? Results from the Health Information National Trends Survey (HINTS). Health Educ Behav 2010 Aug;37(4):490-503. [doi: 10.1177/1090198106296770] [Medline: 17478600 ]

50. Langford A, Resnicow K, An L. Clinical trial awareness among racial/ethnic minorities in HINTS 2007: sociodemographic, attitudinal, and knowledge correlates. J Health Commun 2010;15 Suppl 3:92-101 [FREE Full text] [doi: 10.1080/10810730.2010.525296] [Medline: 21154086]

51. Mayer DK, Terrin NC, Menon U, Kreps GL, McCance K, Parsons SK, et al. Screening practices in cancer survivors. J Cancer Surviv 2007 Mar;1(1):17-26. [doi: 10.1007/s11764-007-0007-0] [Medline: 18648941]

52. Nelson DE, Kreps GL, Hesse BW, Croyle RT, Willis G, Arora NK, et al. The Health Information National Trends Survey (HINTS): development, design, and dissemination. J Health Commun 2004;9(5):443-460. [doi: 10.1080/10810730490504233] [Medline: 15513791$]$

53. Nelson W, Moser RP, Gaffey A, Waldron W. Adherence to cervical cancer screening guidelines for U.S. women aged 25-64: data from the 2005 Health Information National Trends Survey (HINTS). J Womens Health (Larchmt) 2009 Nov;18(11):1759-1768 [FREE Full text] [doi: 10.1089/jwh.2009.1430] [Medline: 19951209]

54. Nguyen GT, Bellamy SL. Cancer information seeking preferences and experiences: disparities between Asian Americans and Whites in the Health Information National Trends Survey (HINTS). J Health Commun 2006;11 Suppl 1:173-180. [doi: 10.1080/10810730600639620] [Medline: 16641082 ]

55. Oh A, Shaikh A, Waters E, Atienza A, Moser RP, Perna F. Health disparities in awareness of physical activity and cancer prevention: findings from the National Cancer Institute's 2007 Health Information National Trends Survey (HINTS). J Health Commun 2010;15 Suppl 3:60-77 [FREE Full text] [doi: 10.1080/10810730.2010.522694] [Medline: 21154084]

56. Rakowski W, Meissner H, Vernon SW, Breen N, Rimer B, Clark MA. Correlates of repeat and recent mammography for women ages 45 to 75 in the 2002 to 2003 Health Information National Trends Survey (HINTS 2003). Cancer Epidemiol Biomarkers Prev 2006 Nov;15(11):2093-2101 [FREE Full text] [doi: 10.1158/1055-9965.EPI-06-0301] [Medline: 17119033]

57. Finney Rutten LJ, Squiers L, Hesse B. Cancer-related information seeking: hints from the 2003 Health Information National Trends Survey (HINTS). J Health Commun 2006;11 Suppl 1:147-156. [doi: 10.1080/10810730600637574] [Medline: $\underline{16641080]}$

58. Shim M, Kelly B, Hornik R. Cancer information scanning and seeking behavior is associated with knowledge, lifestyle choices, and screening. J Health Commun 2006;11 Suppl 1:157-172. [doi: 10.1080/10810730600637475] [Medline: $\underline{16641081]}$

59. Kalichman SC, DiMarco M, Austin J, Luke W, DiFonzo K. Stress, social support, and HIV-status disclosure to family and friends among HIV-positive men and women. J Behav Med 2003 Aug;26(4):315-332. [Medline: 12921006]

60. Sadasivam R. Internet health information seeking is a team sport: Analysis of the Pew Internet Survey. Intl J Med Informatics 2012. [doi: 10.1016/j.ijmedinf.2012.09.008]

61. Dutta-Bergman MJ. Developing a profile of consumer intention to seek out additional information beyond a doctor: the role of communicative and motivation variables. Health Commun 2005;17(1):1-16. [doi: 10.1207/s15327027hc1701 1] [Medline: 15590339$]$

62. Dutta-Bergman MJ. The relation between health-orientation, provider-patient communication, and satisfaction: an individual-difference approach. Health Commun 2005;18(3):291-303. [doi: 10.1207/s15327027hc1803 6] [Medline: $\underline{16187933]}$

63. Dutta-Bergman M. Health attitudes, health cognitions, and health behaviors among Internet health information seekers: population-based survey. J Med Internet Res 2004 May 28;6(2):e15 [FREE Full text] [doi: 10.2196/jmir.6.2.e15] [Medline: 15249264]

64. Powell J, Inglis N, Ronnie J, Large S. The characteristics and motivations of online health information seekers: cross-sectional survey and qualitative interview study. J Med Internet Res 2011;13(1):e20 [FREE Full text] [doi: 10.2196/jmir.1600] [Medline: 21345783]

65. Cooley ME, Sarna L, Brown JK, Williams RD, Chernecky C, Padilla G, et al. Challenges of recruitment and retention in multisite clinical research. Cancer Nurs 2003 Oct;26(5):376-384. [Medline: 14710799]

66. Areán PA, Gallagher-Thompson D. Issues and recommendations for the recruitment and retention of older ethnic minority adults into clinical research. J Consult Clin Psychol 1996 Oct;64(5):875-880. [Medline: 8916614]

67. Mohadjer L, Curtin LR. Survey Methodology.: Government of Canada; 2008. Balancing sample design goals for the National Health and Nutrition Examination Survey URL: http://www5.statcan.gc.ca/olc-cel/olc. action?ObjId=12-001-X200800110618\&ObjType=47\&lang=en [accessed 2015-03-01] [WebCite Cache ID 6fePby5ui]

68. Knobf M, Juarez G, Lee SYK, Sun V, Sun Y, Haozous E. Challenges and strategies in recruitment of ethnically diverse populations for cancer nursing research. Oncol Nurs Forum 2007 Nov;34(6):1187-1194. [doi: 10.1188/07.0NF.1187-1194] [Medline: 18024345]

69. Lillie-Blanton M, Hoffman SC. Conducting an assessment of health needs and resources in a racial/ethnic minority community. Health Serv Res 1995 Apr;30(1 Pt 2):225-236 [FREE Full text] [Medline: 7721594]

70. Yancey AK, Ortega AN, Kumanyika SK. Effective recruitment and retention of minority research participants. Annu Rev Public Health 2006;27:1-28. [doi: 10.1146/annurev.publhealth.27.021405.102113] [Medline: 16533107] 
71. Arora NK, Hesse BW, Rimer BK, Viswanath K, Clayman ML, Croyle RT. Frustrated and confused: the American public rates its cancer-related information-seeking experiences. J Gen Intern Med 2008 Mar;23(3):223-228 [FREE Full text] [doi: 10.1007/s11606-007-0406-y] [Medline: 17922166]

72. Hesse BW, Nelson DE, Kreps GL, Croyle RT, Arora NK, Rimer BK, et al. Trust and sources of health information: the impact of the Internet and its implications for health care providers: findings from the first Health Information National Trends Survey. Arch Intern Med 2005;165(22):2618-2624. [doi: 10.1001/archinte.165.22.2618] [Medline: 16344419]

73. Bilodeau B, Degner LF. Information needs, sources of information, and decisional roles in women with breast cancer. Oncol Nurs Forum 1996 May;23(4):691-696. [Medline: $\underline{\text { 8735327] }}$

74. Houston TK, Allison JJ. Users of Internet health information: differences by health status. J Med Internet Res 2002;4(2):E7 [FREE Full text] [doi: 10.2196/jmir.4.2.e7] [Medline: 12554554]

75. Gracia E, Herrero J. Internet use and self-rated health among older people: a national survey. J Med Internet Res 2009;11(4):e49 [FREE Full text] [doi: 10.2196/jmir.1311] [Medline: 19955041]

76. Rivera-Colón V, Ramos R, Davis JL, Escobar M, Inda NR, Paige L, et al. Empowering underserved populations through cancer prevention and early detection. J Community Health 2013 Dec;38(6):1067-1073. [doi: 10.1007/s10900-013-9715-8] [Medline: 23807496]

77. Gustafson DH, McTavish FM, Stengle W, Ballard D, Jones E, Julesberg K, et al. Reducing the digital divide for low-income women with breast cancer: a feasibility study of a population-based intervention. J Health Commun 2005;10 Suppl 1:173-193. [doi: 10.1080/10810730500263281] [Medline: 16377607]

78. UyBico SJ, Pavel S, Gross CP. Recruiting vulnerable populations into research: a systematic review of recruitment interventions. J Gen Intern Med 2007 Jun;22(6):852-863 [FREE Full text] [doi: 10.1007/s11606-007-0126-3] [Medline: $\underline{17375358]}$

\author{
Abbreviations \\ CMIS: comprehensive model of information seeking \\ CPI: cancer prevention information \\ HINTS: Health Information Trends Survey \\ NCI: National Cancer Institute \\ SES: social economic status
}

Edited by G Eysenbach; submitted 05.09.15; peer-reviewed by $K$ Wright, E Neter; comments to author 19.11.15; revised version
received 09.12.15; accepted 07.01.16; published 09.03.16
Please cite as:
Ginossar T
Predictors of Online Cancer Prevention Information Seeking Among Patients and Caregivers Across the Digital Divide: A
Cross-Sectional, Correlational Study
JMIR Cancer 2016;2(1):e2
URL: $\underline{\text { http://cancer.jmir.org/2016/1/e2/ }}$
doi: $10.2196 /$ cancer.5108
PMID: $\underline{28410177}$

CTamar Ginossar. Originally published in JMIR Cancer (http://cancer.jmir.org), 09.03.2016. This is an open-access article distributed under the terms of the Creative Commons Attribution License (http://creativecommons.org/licenses/by/2.0/), which permits unrestricted use, distribution, and reproduction in any medium, provided the original work, first published in JMIR Cancer, is properly cited. The complete bibliographic information, a link to the original publication on http://cancer.jmir.org/, as well as this copyright and license information must be included. 